\title{
La risa y el 'consuelo intramundano'1: el arte de trascenderse y superarse en Nietzsche
}

\author{
LUIS E. DE SANTIAGO GUERVÓS
}

Todo el mundo no nace como Zaratustra riendo; todo el mundo no nace como Dioniso danzando; todo el mundo no sabe ver como Heráclito que el mundo es un juego divino. W Kauffman llegó a decir que «para Nietzsche la risa representa una actitud hacia el mundo, hacia la vida y hacia uno mismo» ${ }^{2}$. ¿Acaso la risa no conoce y libera, y transfigura el sufrimiento más allá del conocimiento mismo? En realidad, ¿puede haber algo simbólicamente más palpable frente a la seriedad de cualquier pretensión metafísica que la risa? ¿Hay algo que tenga un carácter más liberador, distensionador y expansivo que

1 Sobre la risa en Nietzsche se pueden consultar, entre otras obras, por ejemplo, J. Berger, La risa redentora, Madrid, Kayrós, 1999; M. Cacciari, Desde Nietzsche. Tiempo, arte, política, tr. M. Cragnolini, Buenos Aires, Biblos, 1994, p.108 s.; P. Klossowski, Tan funesto deseo, Taurus, Madrid, 1980, pp. 154-171; J. Lippit, «Nietzsche, Zaratustra and the Status of Laughter», Britisch Journal of Aesthetics, 32 (1992), pp. 39-49; A. Philonenko, Nietzsche. Le rire et le tragique, Paris, LGF, 1995; U. Satlow, Die Bedeutung des Lachen und Tanzens in Nietzsches Zaratustra, Leipzig (Diss.), 1950; M. Cragnolini, «De la risa disolvente a la risa constructiva: una indagación nietzscheana», en M. Cragnolini - G. Kaminsky (eds), Nietzsche actual e inactual, Buenos Aires, Universidad de Buenos Aires, 1996, vol. II, pp. 99-124; G. Vattimo, El sujeto y la máscara, Barcelona, Península, 1989, $154 \mathrm{~s}$.

2 W. Kauffman, The Basic Writings of Nietzsche, New York, Modern Library, 1968, p. 422n. P. A. Gunter señala que «el concepto de risa puede considerarse como una clave de su pensamiento», «Nietzschean laugther», The Sewanee Review, 76 (1968), p. 492. 
la propia risa? Nietzsche sentía esta imperiosa necesidad de la risa, biológica y filosóficamente ${ }^{3}$, como en otro tiempo también la sintió Platón, pues "¿cómo habría podido soportar la vida Platón sin Aristófanes?» ${ }^{4}$. Mathieu Kessler, por ejemplo, afirma que con la risa, Nietzsche sanciona ese vaivén decisivo del dionisismo schopenhaueriano hacia la definición propiamente nietzscheana ${ }^{5}$, que encuentra su modo de ser estético en la elevación por encima de la contradicciones de la naturaleza humana. En este sentido, en la nueva estética que se dibuja en su período intermedio y final, dominado fundamentalmente por las categorías que le proporcionaba el paradigma de la música del Sur, es decir la ligereza del espíritu que se eleva hacia lo más alto, la risa, juntamente con la danza y el juego, forman los recursos estilísticos con los que Nietzsche trata de superar aquella "metafísica de artista" y su lenguaje. Cuando las palabras ya no nos sirven, cuando los conceptos ya gastados no mentan nada, resuena la risa; es la respuesta del cuerpo transformado, la expresión original, más allá del lenguaje y del pensamiento. Por eso Nietzsche prefiere la música y el canto, porque, como la risa y la danza, trasciende el lenguaje. La risa es gesto, pero también es sonido, música sin palabras creada para expresar la alegría y para mofarse de todo el teatro de la

3 Nietzsche confesaba que «sentía verdadera necesidad de alguien que pudiese reír conmigo y que tenga un espíritu expansivo", pues al fin y al cabo la risa viene a ser el simbolismo del SI a la vida. (F. Nietzsche, Sämtliche Werke. Kritische Studienausgabe, ed. G. Colli y M. Montinari, 15 vols., Berlin-München, W. de Gruyter - dtv, 1999, vol. 11, p. 160; de ahora en adelante citaremos esta edición con las siglas KSA seguidas del número de volumen). Epicuro en sus Máximas y pensamiento decía que «cuando se filosofa es preciso reír».

4 MbM §28, p. 54. Citamos por las ediciones de A. Sánchez Pascual, (Madrid, Alianza) con las siguientes siglas: NT: El nacimiento de la tragedia; EaC: Ensayo de autocrítica (1886); HdH: Humano, demasiado bumano; GC: La gaya ciencia; AhZ: Así habló Zaratustra; MbM: Más allá del bien y del mal; CW: El caso Wagner] Nietzsche se refiere a la leyenda que cuenta que cuando murió Platón encontraron bajo su almohada un libro de Aristófanes. Cf. M. Cacciari, Geo-Filosofía de Europa, tr. D. Sánchez Meca, Madrid, Alderabán, 2000, p. 94.

5 Mathieu Kessler, L'esthétique de Nietzsche, Paris, PUF, 1998, p. 71. Por otra parte está suficientemente documentado que hay una coincidencia entre el tratado de Baudelaire sobre La fisiología de la risa y el modo tan extraño con que comienza Nietzsche sus dos escritos contra Wagner, El caso Wagner y Nietzsche contra Wagner, cf. H. Pftotenhauer, Die Kunst als Physiologie. Nietzsche ästhetische Theorie und literarische Production, Stuttgart, Metzler, 1985 , p. 214. 
vida. No es extraño, por lo tanto, que para Zaratustra los maestros del mundo sean los «clowns y los danzadores de cuerda» ${ }^{6}$.

Se puede decir, entonces, que con la risa comienza una percepción invertida de las cosas y de la realidad, otra seriedad inseparable de la alegría del sí ilimitado. La risa implica, entre otras cosas, la desestructuración del armazón conceptual. Como decía Derrida, no se puede luchar contra la razón sino con la razón, pero se pueden tender trampas, estrategias que lleven a la desconstrucción de la clausura del sistema. Lo mismo se podría decir de la risa: no es que signifique la inversión de la irracionalidad o del caos, la risa y la 'ciencia alegre' contribuyen a que el hombre pueda soportar mejor la existencia, o vivir de un modo mucho más 'ligero'. Pero, ¿tiene algo que ver la risa con la creatividad y el arte? La risa produce la 'levedad' del lenguaje, aligera su carga conceptual rígida y pétrea, para hacerlo más flexible y menos dogmático y estático, más danzarín. La risa desestabiliza, quiebra la unidad en una multiplicidad, en perspectivas distintas que abren el mundo a múltiples miradas e interpretaciones que el hombre crea como un nuevo arte de pensar. Frente a la consigna del metafísico, «Non ridere, non lugere, neque detestari, sed intelligere» 7 , Nietzsche vuelve a rescatar la 'risa homérica' que Platón había expulsado aparentemente de su sistema en el Fedón, pues sólo este reír puede detener el nihilismo, en cuanto poder cuasi-trascendental de la transvaloración de los valores.

\section{El PLACER ESTÉtico DE LO TRÁGICO Y LA RisA}

En El nacimiento de la tragedia el 'consuelo metafísico', como recurso simbólico último, era el que fundaba aquella estética que se había elaborado al abrigo categorial de sus principales mentores: Wagner y Schopenhauer. Allí había puesto Nietzsche sus esperanzas en una generación venidera que estuviese dominada por el conocimiento trágico y que en su «autoeducación para lo terrible y la seriedad ${ }^{8}$ hubiese tenido que desear un 'arte nuevo', el arte del 'consuelo metafísico', la tragedia. Sin embargo en el Ensayo de autocrítica (1886)

6 AhZ I, «Del leer y el escribir», p. 70.

7 GC $\$ 333$, KSA 3, p. 558.

$8 \quad$ NT cap. 18, p. 148 
vuelve a retomar el tema, desenmascarando aquellas esperanzas como un síntoma de la enfermedad romántica y de la moral cristiana. Nietzsche apela ahora a las nuevas generaciones a que, ante todo, aprendan «el arte del consuelo intramundano» ${ }^{9}$ que enseña Zaratustra. Y ese arte no es otro que 'aprender a reír', mediante el cual sólo será posible desterrar para siempre cualquier tipo de consuelo metafísico que ofrezca, mediante el arte trágico, 'otro mundo', un más allá de toda apariencia, una esperanza frente al sufrimiento, de tal manera que la vida pueda hacerse de alguna manera soportable. Por lo tanto, la respuesta de Nietzsche frente al consuelismo metafísico del arte trágico es la risa, cuyo lugar está dentro de una visión antimetafísica del mundo, en el más acá de la interpretación de la existencia.

Pero el placer estético de lo trágico se manifiesta también como capacidad de reír, puesto que lo verdaderamente importante es la emancipación de la visión moral y religiosa de la propia tragedia para poder disfrutar de ella como de un espectáculo en el que desaparezca toda compasión o temor. «Ver perecer las naturalezas trágicas y a pesar de eso tener capacidad de reír más allá de toda profunda comprensión, sensibilidad y compasión con ellas... es divino»10. El instinto que crea lo terrible en la vida se convierte en risa, en instinto artístico, como cuando el niño juega creando y destruyendo, transformando en algo bello la tragedia. El hombre trágico, como tal, se ve entonces liberado de la necesidad metafísica de ese consuelo, porque la metafísica ha dejado de ser una instancia consoladora y el ser humano debe buscar compensaciones diferentes. Ahora, «la forma más eficaz de consolarse para aquel que lo necesita es afirmar que su desgracia no tiene consuelo alguno» ${ }^{11}$. Reír es el modo de ser que abre las puertas a una superación de aquella metafísica que buscaba fundamentar inequívocamente una teoría del arte.

En el Ensayo de autocrítica de 1886 aquellas esperanzas consoladoras se interpretan como un síntoma de la 'enfermedad romántica'. Frente al consuelo metafísico que proporcionaba el arte ante la insidiosa sabiduría de Sileno, la vía alternativa a su pensamiento joven no es otra que la compensación estética para un pesimismo radical. Es po-

9 EaC, p. 36.

10 KSA 10, p. 63.

11 Morgenröthe, § 38, en KSA 3, p. 45. 
sible otro consuelo más humano, de un rango superior, pero también artístico, más acorde con la naturaleza de una existencia que ha asumido la vida en todas su dimensiones, y que se abre a una esperanza distinta anunciada por la buena nueva de Zaratustra. Así lo expresa claramente Nietzsche: «Vosotros deberíais aprender antes el arte del consuelo intramundano,... vosotros deberíais aprender a reír, mis jóvenes amigos, si es que, por otro lado, queréis continuar siendo completamente pesimistas; quizás a consecuencia de ello, como reidores, mandéis algún vez al diablo todo el consuelismo metafísico... iy en primer lugar, la metafísica!»12. Nietzsche identifica ya aquí la risa como un 'arte' que dispensa el 'consuelo intramundano' necesario que, a su vez, abre en la etapa crítica de su filosofía una nueva vía estética con un poder capaz de superar y transfigurar al hombre. La risa se convierte, de este modo, en un recurso simbólico dentro de una concepción antimetafísica del mundo y se vincula al proyecto de superación de la metafísica y a perfilar una interpretación de la existencia humana puramente intramundana. Así pues la consolación metafísica que justificaba la práctica de una estética simplemente negativa, se sustituye por la risa, un recurso humano, 'demasiado humano', pues procede de una reacción necesaria de su condición ${ }^{13}$, que significa al mismo tiempo la transformación del simbolismo dionisíaco.

Esta abolición del consuelo metafísico representa y es expresión del nihilismo más radical, pues la esperanza en un más allá ha dejado de fundamentar un mundo vacío de sentido y de valor, en el que sólo el hombre puede re-organizar a modo de artista la naturaleza y crear un orden nuevo. No existe ya ninguna instancia consoladora, porque la metafísica que la sostenía se rechaza como algo meramente ilusorio, con lo cual el ser humano debe buscar otra forma de compensar la tragedia de su destino. «De todos los consuelos ninguno es tan efectivo para quien lo necesita como afirmar que su desgracia no tiene consuelo alguno»14. La risa, por lo tanto, tiene una función estética concreta en el simbolismo que introduce Nietzsche, sobre todo a partir de Zaratustra Se trata del «arte del consuelo intramundano» ${ }^{15}$, en el

12 EaC, p. 36

13 M. Kessler define la risa como una simpatía panteísta, en cuanto que significa la mediación entre el género humano y la singularidad dionisíaca, L'esthétique..., p. 71

14 Morgenröthe, § 380, en KSA 3, p. 247.

$15 \mathrm{EaC}, \S 7$, p. 36. 
que Dioniso aparece ahora como el 'superficial', el más ligero y, ante todo, el más humano.

No es extraño, por lo tanto, que la risa ocupe un lugar de gran importancia en los escritos tardíos de Nitezsche, sobre todo en sus obras de La gaya ciencia y, de una manera especial, en su libro central Así habló Zaratustra. No obstante, ya en Humano demasiado bumano inicia Nietzsche una lucha abierta contra la metafísica desde la perspectiva de una conciencia ilustrada y de una cientificidad históricopsicológica. Esa risa que libera al hombre de la necesidad metafísica del consuelo, que compensa el carácter trágico y doloroso de la vida, rompe con todo lo que pretendía hasta ahora definir al hombre en su esencia. La risa del hombre que afirma el sentido de la tierra como su propia creación no se parece a la de ningún otro, porque es una risa exuberante, que exalta fundamentalmente la vida.

\section{El ESPÍRITU LIBRE: LA RISA COMO FUNCIÓN METACRítiCA}

En el contexto de la crítica antimetafísica de Humano, demasiado humano, y desde una visión psicologista de la realidad humana, Nietzsche plantea el arte desde una perspectiva nueva, antiwagneriana. El lugar que ocupaba el 'genio' en su estética anterior es desplazado por el 'espíritu libre', una figura más representativa de su nueva conciencia crítica e ilustrada. En este nuevo contexto el espíritu crítico del hombre libre, según Philonenko, «muestra que la risa no es una sustancia, sino una función metacrítica que hace la vida posible y, con ella, una existencia auténtica» 16 . La risa es una especie de armadura que protege contra los insultos, las incomprensiones, los desprecios, cuya fuerza crítica es la promesa del devenir, la esperanza de una apertura siempre posible, el signo de transgresiones próximas, de insolencia clara y alegría del futuro ${ }^{17}$. Pero también expresa el proceso de destrucción. La risa arruina el sentido, nos pierde en la medida en

16 A. Philonenko, op. cit., p. 211. Para él esta función "metacrítica” de la risa es fundamental y tiene algo así como un poder trascendental en la inversión de los valores. Sobre el sentido crítico de la risa me remito a la obra de Harold Alderman, Nietzsche's Gift, Ohio, Ohio University Press, 1977, p. 43 ss.

17 Cf. Jaques Sochjer, La question et le sens. Esthétique de Nietzsche, Paris, Aubier, 1972, p. 44. 
que destierra a los «maestros de la finalidad» 18 , privándonos de razones, metas y explicaciones.

Esta asociación de la risa con el espíritu libre y con el poder de la crítica descubre su modo de ser propio en el mundo, que se entiende como una reacción de la existencia, cuando el individuo llega a tener un grado de conciencia de sí mismo. Es un modo particular de ser de la conciencia afirmativa de sí en un mundo que ella descubre como violento, absurdo, o indiferente a su destino. Frente a la tristeza del absurdo y del sinsentido la risa «reafirma nuestro pacto con la vida y con la cultura de la vida»19. Pero también es ella una reacción sana frente al sufrimiento. Por eso se puede entender como la expresión estética de la superación y de la transformación del hombre. Y como todas las categorías 'nuevas' de Nietzsche, que nada tienen que ver con la fijación y esclerosis de los conceptos, también la risa encierra esa ambigüedad consentida que se abre a la pura creatividad. Por un lado soluciona el conflicto y corrige lo irracional, lo inconmensurable y feo para lo razonable, por otro lado contiene lo negativo y denota al mismo tiempo una carencia de medida y serenidad, un 'todavía-no'. Por eso, «la risa — como afirma Mónica Cragnolini- no sólo es el poder disolvente que permite criticar los sistemas anteriores, sino que también es voluntad de construcción: la filosofía del futuro se genera, precisamente, a partir de la risa del niño» ${ }^{20}$. Entonces, se puede decir que el que ríe se encuentra todavía de camino para estar en armonía con el mundo, tratando de dominar lo irracional y lo absurdo de todo aquello que acecha a la vida.

En Humano demasiado bumano se puede observar también cómo la risa está vinculada al espíritu libre y cómo es, en realidad, su respuesta a la filosofía 'seria'. Sólo un espíritu libre sabe reír y, por eso, celebrar las fiestas saturnales de su liberación y de su larga 'enfermedad'. Hasta entonces había sido un esclavo, un espíritu amordazado y atenazado por teleologías impositivas. Ahora se libera del oscuro romanticismo y la risa se presenta como la «alegría frente al sinsentido» (Die Freude am

18 GC $\S 1$, en KSA 3, p. 369.

19 Julio Quesada, El nibilismo activo. Genealogía de la modernidad. Universidad de Guadalajara, 1999, p. 278.

20 Es la tesis que sostiene M. Cragnolini en «De la risa disolvente a la risa constructiva: una indagación nietzscheana», p. 100. 
Unsinn), una vez que el vacío dejado por la 'muerte de Dios' provoca la falta de fundamento. «¿Cómo puede el hombre sentir alegría por lo absurdo? Es el caso que en el mundo se ríe; se puede decir, casi de modo general, que en donde hay felicidad hay alegría por el absurdo. La inversión de la experiencia en su contrario, de lo que tiene un fin en lo que no lo tiene, de lo necesario en lo caprichoso, de tal manera es esto que este fenómeno no hace ningún daño y sólo se representa de un modo humorístico, es un motivo de diversión, pues nos libra momentáneamente de la sujeción a la necesidad, de la adecuación a unos fines y a la experiencia, en los que nosotros de ordinario vemos a nuestros despiadados amos; jugamos y reímos entonces cuando lo esperado (que generalmente trae sombras y tensiones) se realiza sin daño. Es la alegría de los esclavos en las fiestas saturnales» ${ }^{21}$.

Nietzsche pone en relación la risa con el fenómeno de lo cómico y de lo trágico. En lo trágico, el hombre pasa rápidamente de una gran alegría duradera a una gran angustia; mientras que en lo cómico se pasa de una angustia momentánea a una alegría de breve duración. «Pero como entre los mortales la gran alegría duradera es mucho más rara que los motivos de angustia, es por lo que hay mucho más de cómico que de trágico en el mundo; se ríe mucho más a menudo que se llora» 22 . La risa, por lo tanto, se presenta como una consecuencia del absurdo y del sinsentido del mundo y de la existencia. Las cosas privadas del sentido que se les supone, y fuera de su lugar predeterminado por el mundo, provocan nuestra risa. Como dice Kundera ${ }^{23}$, «la risa pertenece pues, originalmente, al diablo. Hay en ella algo de malicia (las cosas resultan diferentes de lo que pretendían ser), pero también algo de alivio bienhechor (las cosas son más ligeras de lo que parecen, nos permiten vivir más libremente, dejan de oprimirnos con su austera severidad)». Por eso, el espíritu libre reconoce que fue el «pensamiento impuro» 24 de la pasión y de la fantasía el que imaginó el valor, el sentido y la finalidad en el hombre y en las cosas, a fin de que la vida pudiera vivirse y toda acción descubriese su meta. De ahí

21 HdH I, § 213, en KSA 2, p. 213.

22 HdH I, § 169, en KSA 2, p. 158.

23 Milan Kundera, El libro de la risa y el olvido, Barcelona, Seix Barral, 1978, p. 96 s.

24 «Toda fe en el valor y en la dignidad de la vida se fundamenta en el pensamiento impuro» HdH I, § 33, en KSA 2, p. 52. 
la 'función correctora' de la risa que se ejerce al demostrar que no hay ninguna relación entre el ser y su apariencia, que lo que aparecía como significativo y con sentido es algo absurdo, una nada, porque más allá de ello no hay más que el vacío. Si se desenmascara el ser como apariencia, la esencia como la nada, el sentido como sinsentido, etc., entonces la existencia se convierte en una verdadera comedia y la risa adquiere su pleno valor. Es la misma risa de los dioses homéricos al contemplar el quehacer de los hombres. Por eso mismo el espíritu libre se ríe de que el hombre quede atrapado en la creencia de que él es el centro del universo y la medida de todas las cosas: «Debería haber criaturas más espirituales que lo que los hombres son, sólo para gustar completamente el humor que yace en el hecho de que el hombre se considere como el centro de todo el universo y que la humanidad declare seriamente de no contentarse más que con la perspectiva de una misión universal» 25 .

El conflicto entre aquellos dos mundos que articulaban metafísicamente la realidad, aparece ahora como un conflicto cómico. Esa oposición se interpreta como pura ficción, puesto que no existen esos dos mundos enfrentados. Así surge lo cómico, como conciencia de la inadecuación del conflicto, como perspectiva desde el espíritu de libertad del espectador que mira sin el pathos trágico de la existencia; porque en realidad no hay nada que sea cómico en sí, sino solo conflictos que aparecen como cómicos, porque el hombre se puede distanciar de ellos y al distanciarse se siente ligero, sereno, y superior. En este sentido, la risa, lo mismo que lo ridículo, tienen su referencia en la esfera subjetiva. Así lo entiende Nietzsche, cuando trata de explicar la risa y lo ridículo en un texto de Aurora: «En otro tiempo se preguntaba: ¿qué es lo ridículo?, como si fuera de nosotros mismos existieran cosas que tuvieran la propiedad de ser ridículas [...] Ahora se pregunta ¿qué es la risa? Reflexionando se ha llegado a la conclusión de que no hay en si nada bueno, nada bello, nada sublime, nada malo, sino más bien estados anímicos que nos hacen atribuir a las cosas que están fuera de nosotros tales palabras» ${ }^{26}$.

Todo lo extraño, los ideales suprahumanos, todo aquello que era objeto de la metafísica, se desenmascara como proyecciones de lo que

$25 \mathrm{HdH}$, II 2, § 14, en KSA 2, p. 548.

26 Morgenröthe, § 210, en KSA 3, p. 190. 
era más próximo, como un producto de errores, de pasiones y autoengaños. Y cuando se descubre la máscara, surge también la risa y la conciencia de sí mismo. El hombre se ha olvidado de su posición, por eso, según Nietzsche, hay que conducirlo de nuevo a la conciencia de su poder sobre el mundo y sobre sí mismo. De este modo, el mundo ya no puede ser entendido como el fenómeno de un ser, sino que se representa como una imagen producida exclusivamente por el hombre y transformada y transmitida a lo largo de una historia. Pero lo que se creía como algo estable y duradero se ha convertido en un 'fábula' y en un eterno devenir. Por eso, «lo que nosotros llamamos actualmente el mundo es el resultado de una multitud de errores y de fantasías, que nacieron poco a poco en la evolución de conjunto de los seres organizados, se entrelazaron en su crecimiento y llegan ahora a nosotros por herencia como un tesoro acumulado de todo el pasado» 27 . Ahora la ciencia y la psicología pueden ayudar a iluminar paso a paso la genealogía de este mundo como representación y hacer que trascendamos los hechos tal y como nos los ha presentado la metafísica. Sólo entonces, dice Nietzsche, podremos reconocer que «la cosa en sí es digna de una risa homérica: que parecía ser tanto, incluso todo, y que está propiamente vacía, especialmente vacía de sentido» 28 . Conviene recordar que Kant asociaba también la risa a la nada: «La risa es una emoción que nace de la súbita transformación de una ansiosa espera en nada» ${ }^{29}$. El propio Kant pone de relieve que para que se de la risa tiene que haber algún absurdo. La risa, por lo tanto, se produce por la falta de sentido inmediatamente reconocida por el espíritu libre que duda del orden de la finalidad y de un más allá del mundo y de las cosas. Nietzsche parafraseando intencionadamente las primeras palabras del Evangelio de San Juan ${ }^{30}$ dice: «la parodia más seria que haya oído jamás es ésta: En el principio era el absurdo, y el absurdo estaba en Dios, y Dios (lo divino) era el absurdo»31. Una manera de reducir el fundamento, el ens supremum al absurdo. Por lo tanto, la risa se considera como una respuesta a la confusión de ser y aparecer, sen-

27 HdH I, § 16, en KSA 2, p. 37.

28 Ibid.

29 E. Kant, Crítica del juicio, ed. M. García Morente, Madrid, Austral, 1997, p. 294.

30 Allí se dice en las primeras palabras del Prólogo: «Al principio era el Verbo y el Verbo estaba en Dios y el Verbo era Dios».

$31 \mathrm{HdH}$, II 1, § 22, en KSA 2, p. 388. 
tido y absurdo y a ella le precede una comprensión cognoscitiva de la inadecuación de las contradicciones. De ahí se sigue que la risa del espíritu libre y su conciencia crítica se condicionen recíprocamente. El conocimiento hace posible la risa y la risa solo se libera con la contemplación del cognoscente. Y con la risa cambia la perplejidad respeto al carácter puramente absurdo de la existencia a la alegría en el absurdo, a la afirmación estética del absurdo.

\section{LA RISA DE LA «GAYA CIENCIA»}

Desde la perspectiva de 1886 Nietzsche afirmaba en el Prólogo a la Gaya ciencia, que Humano, demasiado bumano se podría definir como la época «de una tiranía del dolor sobrepujada aun por la tiranía del orgullo»32. El pensamiento de aquella época había estado «bajo las limitaciones fundamentales de la amargura, lo áspero, lo que provoca el dolor del conocimiento, como prescribía el asco». El espíritu, que se ha opuesto hasta entonces mediante la crítica a una presión terrible, después de una larga 'convalecencia', como suele suceder, se 'ríe' del mundo, celebra las fiestas saturnales de un espíritu enfermo, no libre, que durante mucho tiempo ha resistido los embates de una filosofía 'seria' que trataba de domesticar el espíritu mediante categorías fijas y estables que poco a poco le fueron debilitando: «la gaya ciencia: significa las fiestas saturnales de un espíri$\mathrm{tu}$, que ha resistido pacientemente una terrible presión durante mucho tiempo - paciente, rigurosa, fría, sin someterse, pero sin esperanza- de un espíritu que ahora se ve sorprendido de repente por la esperanza, por la esperanza de salud, por la embriaguez de la convalecencia. Qué puede sorprendernos que con ello salga a la luz mucho de lo irracional y extravagante» 33 . Aquella liberación de la gran presión a la que había sido sometido el pensamiento artístico y creador produce la alegría de la ciencia alegre (Fröbliche Wissenschaft) y las condiciones favorables para que sea posible aquella risa que Nietzsche definió en Humano demasiado bumano como «la alegría del esclavo en las fiestas saturnales» 34 .

32 GC Vorwort, § 1, en KSA 3, p. 346.

33 Ibid.

34 HdH I, § 213, en KSA 2, p. 174. 
Esta 'ciencia alegre' tiene mucho de parodia frente a una metafísica que se erige como saber 'serio', grave y fundamentado, que se hace como hay que hacerlo, con todas las garantías para proporcionar seguridad frente al devenir de la existencia 'explicándolo' todo, a fin de hacernos creer que la vida tiene un sentido, un fin, un orden. Nietzsche quiere poner de relieve aquí, que existe un verdadero prejuicio al creer que el pensamiento está ligado siempre a la 'seriedad', a 'tomar en serio el asunto' del pensar. Esa pesada máquina que es el intelecto rechina y 'pierde el buen humor' cuando se relaciona con las cosas, pues la mayoría de los hombres piensa que «donde hay risa y jovialidad nada vale allí pensar»35. La alegría de la ciencia alegre es, por ello, en primer lugar un signo para la liberación de la 'larga presión' de una ascesis que aparta al pensamiento creador; es una fiesta «después de una larga carestía e impotencia» y anuncia que todavía hay un futuro para la risa ${ }^{36}$. Pero 'el alegre saber' no deja de ser un arte, y como todo arte no busca precisamente la sistematización. La risa es un arte porque nos capacita para ir más allá de nosotros mismos, porque solo se puede reír de lo que ha sido ya superado, cuando el horizonte está abierto a perspectivas infinitas y siempre nuevas.

Parece obvio, por lo tanto, que la risa tenga un importante significado en una obra que tiene como título la Gaya ciencia. La risa se afirma ahora en este escrito de Nietzsche como la señal de una filosofía creadora. El espíritu libre no se contenta con la mera crítica destructiva de los ideales trascendentes inherentes a la metafísica y a la moral, sino que mediante la risa afirma la comedia de la existencia como un espectáculo en el que también él participa. Dice sí al sufrimiento inherente a la vida y se entrega a las tensiones y contradicciones en el devenir del más acá, pero esa afirmación no es peyorativamente trágica, sino que está contaminada por esa 'risa buena' que ofrece, por una parte, alegría, distensión y ligereza, y por otra parte descubre lo grave, la tensión y lo lúgubre, de los que quiere liberarse de momento el que se ríe. Por lo tanto, Nietzsche considera que sólo en la 'Gaya ciencia' la risa cumple la función atribuida en el Ensayo de autocrítica, es decir, ser «el arte del consuelo intramundano», y en esa

35 Cf. GC, § 327, en KSA 3, p. 555.

36 J. Quesada, «Nietzsche: risa, genealogía, carnaval. El teatro del 'yo'», en AA.VV., Actualidad de Nietzsche, La Coruña, 1994, p. 60. 
medida hay que comprenderla también como un elemento de «redención» 37 y justificación intramundano: riendo, el espíritu libre 'se trasciende' a sí mismo y se contempla como una figura estética: «Tenemos que descansar de nosotros mismos, cuando nos miramos desde arriba o desde abajo y, a una distancia estética, nos reímos de nosotros, o lloramos por nosotros: Tenemos que descubrir al héroe lo mismo que al loco, que se oculta en nuestra pasión por el conocimiento, tenemos que dejar a un lado nuestra necesidad y ser alegres, para que pueda seguir siendo alegre nuestra sabiduría. Y justamente porque nosotros en último término somos hombres serios y graves y más ponderación que hombres, entonces nada nos sienta mejor que la gorra del bufón: la necesitamos para nosotros mismos- necesitamos todo arte travieso, flotante, bailarín, burlesco, infantil y alegre, para no privarnos de esa libertad sobre las cosas, la cual reclama de nosotros nuestro ideal» 38 .

El espíritu libre necesita, por lo tanto, un arte que sea ligero, capaz de elevarse por encima de los condicionantes a los que se veía enfrentado en su enfermedad, pero ser ligero no significa extraño ni alienado; esa ligereza tiene que ser como la de la risa, que es «superficial», porque es «profunda»39, es decir, en su superficialidad refleja lo profundo. Nietzsche retorna de nuevo a la dialéctica que le había servido de modelo para explicar el arte en el marco de una metafísica, la 'metafísica de artista'. Sin embargo la 'bella apariencia del arte' no es la superficialidad de la risa, pues la risa, ciertamente, nos libera del sufrimiento, pero al mismo tiempo expresa ese sufrimiento. En otros términos. La risa produce un distanciamiento de las cargas más pesadas, que no permiten al hombre elevarse por encima de sí mismo o superar el sufrimiento que continuamente le acecha, pero este alejamiento es al mismo tiempo aproximación y conciencia de lo que es pesado, del enredo, de la confusión, todo aquello de lo que aparentemente se liberaba: «Quizás yo sé mejor que nadie por qué el hombre es el único ser que ríe; él es el único que sufre tan profundamente, que tuvo que inventar la risa. El

37 Sobre la dimensión cómica de la experiencia humana Peter Berger ha señalado como algo fundamental de la risa su 'promesa de redención': Risa redentora, Barcelona, Kairós, 1998.

38 GC, § 107, en KSA 3, p. 464.

39 GC, Vorwort, § 1, en KSA 3, p. 346. 
animal más desgraciado y más melancólico es exactamente el más alegre» 40 . Y un poco más adelante añade: «El animal que más sufre sobre la tierra se inventó la risa»41.

El espíritu libre constituye el mundo desde una distancia como «fenómeno estético» ${ }^{42}$. Su amplia mirada no está condicionada por la identificación con el ojo absoluto del mundo alcanzada en el trascender, sino por la ligereza del contemplador adquirida por la risa de la liberación: «Hay que ser muy ligero como para mover su voluntad al conocimiento en una lejanía semejante y al mismo tiempo para estar por encima de su época, para crear sobrepasando miles de ojos»43. Y desde la altura se contempla como un 'payaso', o como un 'loco' (que está fuera de sí), en los que se refleja el absurdo del mundo; oteando su «ilimitada pobreza de mosca y de rana» 44 reconoce su nada y se ríe de sí mismo, aniquilándose en esa nada, pero al mismo tiempo se pone a sí mismo algo que se ha de afirmar. Nietzsche lo expresa en estos términos: «Reírse de si mismo, como uno tendría que reírse, para reírse desde fuera de la verdad total, para esto los mejores no tenían hasta ahora bastante sentido de la verdad y los mejor dotados demasiado poco genio. ¡Tal vez existe un futuro todavía para la risa! Luego, si la frase "la especie es todo, lo uno es siempre ninguno" se ha incorporado a la humanidad y se abre en todo momento a cada uno el tránsito a esta última liberación e irresponsabilidad. Quizás entonces se hayan unido la risa con la sabiduría, quizás entonces haya sólo todavía 'una ciencia alegre'»45. Una ciencia que valora riendo, que se aventura en la vida jugando con ella; y esto quiere decir apolinismo entretejido dionisíacamente, unión del querer y el conocer en el hacer de una sabiduría que ríe.

Como se puede apreciar por estos testimonios, de nuevo se afirma la copertenencia de las esferas del sufrimiento y del placer, de la vida y del conocimiento, con un transfondo no explícito de la dialéctica de lo apolíneo y de lo dionisíaco. En la risa, lo mismo que en la tragedia, juegan uno y otro extremo indistintamente, se median y se reconci-

\footnotetext{
40 KSA 11, p. 571.

41 KSA 11, p. 576; VP § 990.

42 GC $\S 107$, en KSA 3, p. 464.

43 GC $\S 380$, en KSA 3, p. 633

44 GC $\S 1$, en KSA 3, p. 369.

45 Ibid.
} 
lian, son puestos lúdicamente de acuerdo y permanecen igualmente presentes en su carácter contradictorio. Pero la diferencia entre aquella polaridad que estructuraba su 'metafísica de artista' y ésta se cifra en que el acento ahora se desplaza al momento apolíneo de la libertad, del conocimiento y de la distancia; la risa es la señal de una superación y sometimiento de la vida ciega, que quiere a través de la conciencia de un pensamiento que experimenta lúdicamente. «La vida un medio de conocimiento. ¡Con este principio en el corazón uno no sólo puede vivir valientemente sino incluso alegremente y reír alegremente! ¿Quién entendería bien de algún modo el reír y el vivir? ¿Aquél que se comprendiese bien antes en la guerra y en la victoria?»46. No obstante, a pesar de esa superioridad del campo apolíneo de la libertad y del conocimiento que se expresa en la risa, sin embargo también es relativizada y limitada desde el campo de lo dionisíaco; la vida puede llegar a ser ciertamente un medio del que conoce, siempre que el conocimiento esté al servicio de la vida. Por otra parte, la represión del sufrimiento en la risa o el efecto destructivo y creador de la 'sonrisa correctora' dan testimonio de que el elemento de lo dionisíaco comienza a aflorar de nuevo en el pensamiento de Nietzsche y retorna otra vez la función primordial que ejercen la fuerzas creadoras en el ámbito de la concepción del mundo y de la existencia ${ }^{47}$.

Por eso, el espíritu libre para Nietzsche, como el loco, ha de filosofar a carcajadas como expresión de su escepticismo total por la falta de fundamento. Su relación con el mundo y con la historia sigue estando mediada por el gran acontecimiento de la 'muerte de Dios'. El espíritu libre y el filósofo ante la noticia de la 'muerte de Dios' responden jugando y riendo. Un acontecimiento de estas características no proporciona simplemente tristeza o desasosiego, sino todo lo contrario, pues, como dice Nietzsche: «por fin se permite a nuestros barcos zarpar de nuevo en dirección hacia cualquier peligro [...] la mar, nuestra mar se presenta ante nosotros de nuevo abierta. Es posible que no haya habido nunca todavía un 'mar tan abierto'»48. Ni el filósofo ni el espíritu libre se avergüenzan de su risa, porque es inocente, está

46 GC $§ 324$, en KSA 3, p. 553.

47 Sobre la fuerza creativa y contemplativa véanse algunos de los aforismos de la Gaya ciencia, por ejemplo: $\S 301$.

48 GC $\S 343$, en KSA 3, p. 574. 
más allá del bien y del mal y sigue «el ideal de un espíritu que juega ingenuamente con todo, es decir sin pretenderlo, desde una plenitud $\mathrm{y}$ un poder sobreabundante, lo que hasta ahora se considera santo, bueno, intocable, divino» ${ }^{49}$. Jugando en un juego afirma su ambigüedad de libertad y prisionero, y constituye el mundo como una comedia. Es la ambivalencia de la vida que se produce como consecuencia de la 'muerte de Dios'. La contraposición entre la esfera del más acá y del más allá desaparece y con ello caen todas las contradicciones mezclándose en fenómenos ambivalentes: ser y aparecer, verdad y no verdad, sentido y absurdo, finalidad y azar, tiempo y eternidad, necesidad y contingencia. Todas ellas juegan mezclándose en la unidad de doble valor y doble visión, unidad que Nietzsche llama la 'vida'. Y el espíritu libre reacciona frente a esta ambivalencia de la vida pura del más acá con la risa. Su comportamiento tiene doble sentido, lo mismo que el mundo con el que se relaciona, y trata de mantenerse en este 'entre' (zwischen) jugando y riendo. No es extraño, por tanto, que la categoría de la risa alcance un lugar privilegiado en la descripción del 'espíritu libre', y que adquiera rasgos de categoría estética como la actitud fundamental del hombre frente a la vida y la existencia, despojadas ahora de la 'seriedad' y rigidez del fundamento. M. Kundera decía que «la risa es la expresión del ser que se alegra de ser» ${ }^{50}$, porque cuando ríe nos está diciendo que 'vive profundamente'.

\section{Zaratustra EL MAESTRO DE LA RISA: LA RISA QUE TRANSFORMA}

La risa, como 'teoría del arte del consuelo intramundano', alcanza su máxima expresión y significado en Así babló Zaratustra. Nietzsche se sirve de Zaratustra, el profeta, «el único hombre que rió el mismo día que nació», según Plinio, para transmitir uno de los componentes esenciales de su estética de la ligereza, la risa. Zaratustra es el filósofo que ríe. Para él la belleza y el conocimiento poco valen si no se les une la risa ${ }^{51}$. Él es también el maestro que enseña a reír para hacer al hombre más ligero, más alegre, dispuesto a volar y a danzar por encima de todas las cosas, y a superarse a sí mismo. Casi todos los pasajes

49 GC $§ 382$, KSA 3, p. 365

50 M. Kundera, op. cit., p. 90.

51 AhZ, IV, «La sombra», p. 365. 
en los que se habla de la risa en esta obra reflejan, en cierta medida, no solamente el espíritu de su autor y el grado de desarrollo de su pensamiento, sino también la posición estética del hombre frente al mundo y sus problemas existenciales. Zaratustra, el poeta y bailarín, personifica un espíritu que se eleva en la alegría loca a lo más alto de la inmanencia y allí juega un juego con las cosas bromeando y riendo. Este sesgo lúdico es precisamente lo que le distingue del ideal del espíritu libre tal y como lo proyecta en Humano, demasiado bumano y lo amplia la Gaya ciencia. Mientras que el espíritu libre trata de deshacerse de los valores que han tenido vigencia hasta ahora, permaneciendo crítico frente a ellos y tratando de evitar su carácter condicional, Zaratustra realiza su libertad como libertad para los nuevos valores y nuevas condiciones, como libertad ante la ley. No es ciertamente la libertad del león, que es la del espíritu libre, sino la libertad del niño que ríe, juega y crea. Con esta nueva perspectiva estética de su filosofía, bajo la mirada y la permanente sonrisa de Zaratustra, Nietzsche cree haber cumplido artísticamente en esta obra, lo que a Wagner le faltó: «la gaya ciencia, los pies ligeros; bromas, fuego, donaire; la gran lógica, el baile de las estrellas; la espiritualidad petulante; la estremecedora luz del sur, la mar plana... perfección» ${ }^{2}$. De esta forma, el principio supremo de su última estética, la ligereza o levedad — «El bien es ligero, todo lo divino corre con pies ligeros: primer principio de mi estética»53- queda asociado a la risa productiva del poeta Zaratustra, expresión de un juego inocente, travieso, pero enormemente creativo.

Nietzsche, de este modo, concede a la risa un valor estético fundamental, que se asocia a una nueva estética que se genera paralelamente a la transvaloración de los valores. La risa es la salud del gran cansancio; la liberación de la presión que ejerce la ascesis para el asceta del pensamiento, que busca la proximidad de las cosas; la alegría del convaleciente. Es la respuesta a ese "concienzudo del espíritu»54, que se enfrenta a las cosas con una dureza, seriedad y rigor como nadie; y se interpreta como un remedio contra la compasión, pues con la risa se produce la distancia respecto al sentimiento y a la moral.

52 CW $\S 10$, en KSA 6, p. 35.

$53 \mathrm{CW} \S 1$, en KSA 6, p. 13.

54 AhZ IV, «La sanguijuela», p. 337. 
Pero además, Zaratustra la presenta como la primera reacción a un mundo sin fundamento, sin fondo, ante el escenario vacío que ha producido la falta de relación entre ser y significado. Es la liberación frente al absurdo y el sinsentido de la existencia, frente a la nausea que produce el vacío de la mentira total de un mundo inauténtico. Pero el problema está en que 'reír', como ríe Zaratustra, es algo que no nos es dado, sino que hay que aprender. Para Nietzsche, sus contemporáneos son los que todavía no han aprendido a reír, es decir, los que se disfrazan de románticos, de clásicos, de cristianos, o de nacionales, pero que en el fondo han perdido toda esperanza. Sin embargo ninguna otra época ha estado mejor preparada que ésta para recibir desde su desesperación y 'nausea' al que ha de venir. Zaratustra anuncia a estos desesperados la venida de alguien que «vuelva a hacer reír, un payaso alegre, un bailarín y un viento, un hombre travieso, algún viejo necio»55. Y nosotros, responde Nietzsche, «estamos preparados como ningún otro tiempo lo estuvo, para el carnaval de gran estilo, para la más espiritual petulancia y risotada de carnaval, para la altura trascendental de la estupidez suprema y de la irrisión aristofanesca del mundo. [...] ; tal vez, aunque ninguna otra cosa de hoy tenga futuro, téngalo, sin embargo, precisamente nuestra risa!»56.

Y precisamente, porque el futuro y la esperanza pertenecen a la risa, Zaratustra tratará de adoctrinar sobre todo a los 'hombres superiores', para que se superen y trasciendan a sí mismos y abran el camino hacia el superhombre. En la IV parte de Así habló Zaratustra es donde mejor se aprecia esta estética de la risa, y donde llega a su culminación, como complemento a esa otra idea subyacente, que es la relación entre el crear y el juego. Dirigiéndose a esos 'hombres superiores', Nietzsche por boca de Zaratustra les aconseja que aprendan a bailar, pero sobre todo a reír: «¡Cuántas cosas son posibles aún! ¡Aprended, pues, a reíros de vosotros sin preocuparos de vosotros! Levantad vuestros corazones, vosotros buenos bailarines, jarriba! ¡más arriba! ¡Y no me olvidéis tampoco el buen reír! / Esta corona del que ríe, esta corona de rosas: ja vosotros, hermanos míos, os arrojo esta corona! Yo he santificado el reír; vosotros hombres superiores, aprended de mi... a

55 AhZ IV, «El saludo», p. 373.

$56 \mathrm{MbM} \S 223$, p. 168 
reír!»57. Esa 'corona de rosas' que es la risa, arrojada a esos hombres elegidos, simboliza la experiencia viviente de una contradicción existencial: el esplendor de la belleza y la perversidad de las espinas. Sin sus espinas la rosa sería algo vulgar. A la exuberancia y vitalidad exaltada de la risa también pertenece el sarcasmo, aquello que se alimenta de la destrucción del sentido, las espinas de esa corona.

Estos 'hombre superiores', a los que Zaratustra quiere enseñar a reír, son los tipos del 'nihilismo pasivo'. A ellos les falta la fuerza necesaria para crear nuevos valores y nuevas metas, son los «hombres del gran anhelo, del gran asco, del gran hastío», el «último resto de Dios sobre la tierra». Estos seres son los que todavía presagian la «nueva y bella especie», los «leones rientes» que tienen que venir ${ }^{58}$; pero en su anhelo y en sus dudas aún actúa Dios. Zaratustra quiere despertarlos de su sueño complaciente, enseñándoles a reír tal y como él ríe, porque la risa del hombre superior no es su risa, ya que la verdadera risa 'cura'. Ellos ciertamente ríen, pero todavía ríen a su manera y parece que están alegres. Ahora bien, «si ellos aprendieron de mí a reír, - dice Zaratustra - no es $m i$ risa, sin embargo, la que han aprendido»59 ¿Qué sentido tiene, entonces, la risa de Zaratustra? ¿Qué diferencia hay entre esas dos formas tan distintas de reír? ¿Por qué ellos no han aprendido todavía su risa?

La risa de Zaratustra pertenece a las saturnales de una libertad para nuevas condiciones, mientras que la risa del hombre superior sólo es la risa en las saturnales por haberse liberado de toda condición, la distensión del esclavo. En un primer grado este modo de reír se acredita como un medio del aligeramiento de la carga que representa la nueva doctrina, sobre todo la idea del eterno retorno; son las fiestas saturnales de un espíritu que se prepara «para la larga y terrible decisión» ${ }^{60}$. El siguiente paso expresaría la realización de las ideas dominantes de la doctrina, es la expresión de alegría de aquel que ha superado la idea más terrible y más asfixiante — la del eterno retorno—, y es capaz de la superación en el sentido de la voluntad de poder; y su

57 AhZ IV, «Del hombre superior», p. 394. Este mismo texto es recogido por Nietzsche al final de su Ensayo de autocrítica como respuesta y alternativa estética a la 'metafísica de artista' que desarrolló en El nacimiento de la tragedia. Cf. EaC, p. 36.

58 AhZ IV, «El saludo», p. 377.

59 AhZ IV, «El despertar», p. 412.

60 GC, Vorwort, § 1, en KSA 3, p. 345. 
poderosa potenciación se transforma en una explosión de alegría desbordante que posibilita las condiciones de una nueva forma artística de crear. Pero para que el hombre se transforme creativamente, es necesario que se convierta en un artista cuyo resultado no sería otro que «esa obra de arte» fruto de su propia autosuperación. «El cambio de los valores — dice Zaratustra-, eso es el cambio de los creadores ${ }^{61}$. Pero al mismo tiempo el propio Zaratustra ordena que para ser esos creadores poseídos de la 'loca alegría' es necesario superar el pasado mediante el poder destructor que también tiene la risa: «No con la cólera, sino con la risa se mata» ${ }^{2}$, se disuelven y desacralizan los valores pasados: «Y los mandé derribar sus viejas cátedras y todos los lugares en que aquella vieja presunción se había sentado; los mandé reírse de sus grandes maestros de virtud y de sus santos y poetas y redentores del mundo. De sus sombríos sabios los mandé reírse y de todo el que alguna vez hubiera posado, para hacer advertencias, sobre el árbol de la vida como un negro espantajo. Me coloqué al lado de su gran calle de los sepulcros e incluso junto a la carroña y los buitres... y me reí de todo su pasado y de su mustio y arruinado esplendor. En verdad semejante a los predicadores y penitenciales y a los necios grité yo pidiendo cólera y justicia sobre todas sus cosas grandes y pequeñas... jes tan pequeño incluso lo peor de ellos! —así me reía» 63 .

Para Nietzsche, por lo tanto, la superación del hombre depende, por lo tanto, de que sepa reírse de sí mismo, es decir, que aprenda a valorar su falta de significado. Pero todavía son muchas cosas posibles y todas ellas dependen de este consejo de Zaratustra: «iAprended a reiros de vosotros mismos como hay que reír!» 64 , porque riéndose es como el hombre puede distanciarse de sí mismo y elevarse por encima de sí mismo; riéndose se puede corregir la fealdad y la nausea por el ideal de belleza, « A Aprended, pues, a reíros de vosotros sin preocuparos de vosotros!»65. La risa hace posible que lo bello se oponga a lo feo, puesto que al reírse por encima de sí mismo y potenciarse, es como si viera la belleza del superhombre, cuyo exceso le vale como medida.

61 AhZ I, «De las mil metas y de la única meta», p. 96.

62 AhZ I, «Del leer y escribir», p. 71.

63 AhZ III, «De las tablas viejas y nuevas», p. 274.

64 AhZ IV, «Del hombre superior», p. 390.

65 Ibid., p. 394. 
Pero la superación del hombre hacia el superhombre requiere también como condición previa la afirmación del eterno retorno y la superación del 'asco' en la forma absurda de un eterno devenir siempre igual. Esto es lo que enseña Zaratustra en «De la visión y el enigma». El encuentro del hombre con la idea del eterno retorno se escenifica en la parábola del pastor, en la que aparece éste tendido en el suelo, desesperado y gritando, con una «serpiente negra y pesada» que se había introducido en su boca. «¿Había visto yo alguna vez tanto asco y tanto lívido espanto en un solo rostro?» 66 . El pastor, entonces, «mordió, tal como se lo aconsejó mi grito» y «lejos de sí escupió la cabeza de la serpiente:... y se puso en pie de un salto». Superando el asco ante la idea más pesada y tenebrosa posible, se supera con ello a sí mismo y se libera en la superación con una risa, que alcanza a lo más alto, porque procede de lo más profundo y lo más pesado, y entonces lo más pesado y lo más negro se transforma en la claridad y serenidad. Zaratustra jamás había oído reír a nadie sobre la tierra como reía aquel pastor. Los efectos de su poder son tales que metamorfosean y transfiguran, porque la risa viene a ser como la alquimia de la transformación del resentimiento en afirmación exuberante de sí, redime de lo absurdo y lo negativo67. Este reír inédito sobre la tierra es el reír de la libertad, de esa libertad que define al hombre en tanto que ríe. «Ya no pastor, ya no hombre,... jun transfigurado, iluminado que reía! ¡Nunca antes en la tierra había reído hombre alguno como él rió! / Oh hermanos míos, oí una risa que no era risa de hombre,..... y ahora me devora una sed, un anhelo que nunca se aplaca. / Mi anhelo de esa risa me devora: ¡oh, cómo soporto el vivir aún! ¡Y cómo soportaría el morir ahora!...»68.

La redención y superación del hombre ya no es entonces posible ni a través de la religión, ni a través del arte trágico, sino por la fuerza de la ligereza de la risa que eleva el espíritu hacia lo más alto, hacia esa 'sabiduría de pájaro', que enseña Zaratustra. Se trata de esa altura que ha neutralizado todas las contradicciones, las oposiciones entre ser y apariencia, necesidad y contingencia, superficial y profundo. Es el intramundo dionsíaco donde todo se vuelve ambiguo y de doble

66 AhZ III, «De la visión y el enigma», p. 227.

67 M. Kessler, op. cit., p. 66.

68 Ibid., p. 228. 
sentido, donde «medianoche es también mediodía,... dolor es también un placer, la maldición es también bendición, la noche es también sol[...], un sabio es también un necio» ${ }^{69}$. Pero esa altura es también la morada de la risa que marca la distancia respecto a lo superado, la «risa de la altura»70, a la que Nietzsche le está en cierto sentido concediendo un lugar privilegiado, que manifiesta simbólicamente la respuesta a todo lo que se sitúa bajo las negras y graves nubes de lo absurdo. "Yo ya no tengo sentimientos en común con vosotros: esa nube que veo por debajo de mí, esa negrura y pesadez de que me río,... cabalmente es vuestra nube tempestuosa. Vosotros miráis hacia arriba cuando deseáis elevación. Y yo miro hacia abajo, porque estoy elevado. ¿Quién de vosotros puede a la vez reír y estar elevado? Quien asciende a las montañas más altas se ríe de todas las tragedias, fingidas o reales» ${ }^{11}$.

Es la risa, por lo tanto, la que arrastra lejos, hacia arriba, hacia fuera; «es una explosión — como dice Kundera- que nos arranca del mundo y nos deja tirados en nuestra fría soledad»72; es ella la que impulsa hacia también «sures más ardientes con los que los artistas no soñaron jamás». El gran anhelo acompaña a la risa hacia ese lugar donde los dioses bailan, en donde la ligereza hace que hasta los dioses se avergüencen de ir vestidos. Pero, para Nietzsche, esa «risa de la altura» es también la «risa de lo profundo». «Llevar a lo alto lo profundo», decía Zaratustra, porque «todo lo profundo debe ser elevado»73, puesto que cuanto más profundo llega el saber por la verdad terrible, tanto más grande puede ser la 'loca alegría' (Übermut), tanto más ligera puede ser la serenidad. Y al revés, cuanto más alta sea la petulancia, más profundo se va la mirada hacia el abismo. «La profundidad — dice Zaratustra - resplandece de enigmas y risas flotantes ${ }^{74}$. La serenidad de las alturas es lo que no tienen el cazador del

69 AhZ IV, «La canción del noctámbulo», p. 428.

70 AhZ II, «De las tarántulas», p. 151.

71 AhZ I, «Del leer y escribir», p. 70. Éste es el lema con el que Nietzsche introduce la tercera parte de su obra, lo cual da entender la importancia que tiene para él la risa al ponerla en relación con las "alturas" como símbolo de la libertad de mirar, comprender y actuar.

72 Milan Kundera, op. cit., p. 207.

73 AhZ II, «Del inmaculado conocimiento», p. 184.

74 AhZ II, «De los sublimes», p. 174. 
«bosque del conocimiento», ni el penitente del espíritu, ni los sublimes de agitada pasión, ni el hombre superior, porque todavía no «han aprendido la risa ni la belleza»75 y su conocimiento «todavía no ha aprendido a sonreír»; y es por ello, por lo que los ciegos impulsos no se han vuelto serenos en la belleza, pues para una voluntad violenta la belleza es inalcanzable pues exige serenidad. Y para comprender esta mezcla de altura y profundidad, placer y dolor, que produce una unidad ambivalente y ambigua como consecuencia de la inseparabilidad de las esferas, Nietzsche compara a los hombres con los 'árboles': cuanto más crecen más profundas se hacen sus raíces, «cuanto más quiere elevarse hacia la altura y hacia la luz, tanto más fuertemente tienden sus raíces hacia la tierra, hacia abajo, hacia lo oscuro, lo profundo,... hacia el mal» ${ }^{76}$. Con la risa el mal de lo profundo y la bienaventuranza de la altura juegan indistintamente, pues «dentro de la risa, en efecto, se congrega todo lo malvado, pero santificado y absuelto por su propia bienaventuranza» 77 , en ella se mezclan placer y sufrimiento en una ambivalencia dionisíaca del sentimiento. Nietzsche parece querernos decir con ello que la risa, lo mismo que lo dionisíaco, puede también expresar adecuadamente la unidad de todos los contrarios, el mundo de la voluntad de poder. La verdad de la voluntad de poder, es decir su unidad consigo misma en su carácter contradictorio, puede ser comprendida en la risa, porque también la risa une en sí lo contradictorio y el acuerdo. Por eso Zaratustra se llama a sí mismo alguien que «ríe la verdad» 78 , porque en él se han juntado en una nueva unidad «las fuerzas más altas y más bajas de la naturaleza humana, lo más dulce, ligero y terrible brota de un manantial único con inmortal seguridad» 79 . En última instancia es la voluntad de poder la fuerza que hace posible que riamos como hay que reír, porque la risa de verdad, la 'risa de altura' es la que exterioriza la alegría desbordante o la plenitud vital, al mismo tiempo que es la afirmación excedentaria de la destrucción, de lo que sobrevive para destruirse y reaparecer.

75 Ibid.

76 AhZ I, «Del árbol de la montaña», p. 72.

77 AhZ IV, «De los siete sellos», p. 317.

78 AhZ, IV, «Del hombre superior», p. 392.

79 EH «Así habló Zaratustra», § 6, p. 101. 